clinical relevance, because many human cardiopulmonary diseases are characterized by chronic hypoxia. Furthermore, with the ever increasing availability of air travel, clinicians have to be aware of the problems of high altitude and their patients' disease.

This book is particularly pleasing to read because the authors have a very engaging and lively style heightened by their many personal experiences in the Andes and have broadened its authority by an extensive reference section at the end of most chapters. These references are particularly valuable for they deal not only with the historical aspect of the subject, but also include recent references of high altitude investigation.

As outlined by Sir Cyril Clarke in his foreword, Nature has produced a ready-made experiment for mankind in the environment of Man at High Altitude. The effect of high altitude on the physique of man, on the ventilation/perfusion performance of the lungs, of high altitude on blood rheology, the carotid bodies and the pulmonary vasculature is particularly interesting to read. Actual disease entities produced by high altitude such as acute mountain sickness, high altitude pulmonary oedema and Monge's disease form instructive chapters. The effect of high altitude on all organ systems is reviewed with particularly good sections on the cardiovascular system and endocrine systems.

Chapters on the adaptation and acclimatization to high altitude are relevant to modern medical practice with a further interesting section on athletic performance at moderately high altitudes, as exemplified by the Olympic Games in Mexico City.

This book can be highly recommended, not only for the high educational content on the effect of man at high altitude, but also for its pleasing literary style enhanced by the unique personal experiences of the authors. It should be of interest to a wide spectrum of medical readers both at the undergraduate and postgraduate level.

\section{Medical Data Interpretation for MRCP}

By Roger Gabriel and Cynthia M. Gabriel. Pp. 162, illustrated. Butterworths: London, etc., 1978. $£ 2.95$.

This, the latest of many recent publications designed to provide succour for those battling in the MRCP exam, is intended to give practice in the written section of Part II. There are 10 chapters, each one devoted to a speciality such as Cardiology or Renal Disease with, on average, 30 items in each. These consist usually of a short clinical problem followed by a number of questions. The answers, with explanations, are given in the second half of the book.

The relevance to clinical realities of considering highly selected data in isolation such as the cardiac index, or being asked to suggest a diagnosis when give-away data such as heel/pad thickness, are provided, is doubtful. There are also problems raised by discussion of an often limited differential diagnosis or by thumb-nail sketches of management which are in many instances, far too dogmatic. Although these faults may largely reflect the format of the book, there are also a number of errors of fact. The electrocardiographic data are particularly weak. We are told that a massive $R$ wave in $V 1$ is seen in acute pulmonary embolism, that voltage criteria for left ventricular hypertrophy hold with left bundle branch block, and that an ECG showing a sinus arrhythmia is a sinus bradycardia.

There are also a remarkable number of spelling mistakes, many of which are repeated consistently and of which "atopic ACTH production" is perhaps the gem.

This book achieves the authors' aims of providing a stimulating means of studying for the exam but until a second edition has eliminated the errors of fact and of spelling it cannot wholeheartedly be recommended.
1001 Multiple Choice Questions and Answers in Surgery

A. J. Harding Rains. Pp. 221. H. K. Lewis: London, $\frac{\varrho}{\gtrless}$ 1978. $£ 4.00$.

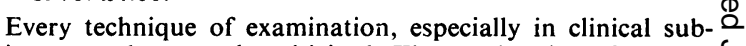
jects, can be severely criticized. The marks given for essay $\complement$ questions are notoriously variable from one examiner to the $\overrightarrow{\vec{B}}$ other and indeed it has been known for the same examiner $\stackrel{\text { f }}{\rightarrow}$ marking the same essay question on different occasions to vary the mark from "distinction" to "fail"! Patients provided 등 for long and short clinical cases vary considerably in their $\overline{\bar{\omega}}$ their ability to give a reasonable history and the ease or $\frac{\overrightarrow{ }}{\overrightarrow{0}}$ difficulty of their physical signs. Some of the "pots" used in $\unrhd$ pathology vivas, if shaken, look like those glass toys of the Eiffel Tower in a snow storm. Multiple choice questions, with all their faults, at least provide a strictly comparable $\overrightarrow{0}$ situation to every candidate, are marked impartially by the computer and enable a wide range of the factual knowledge $\vec{\omega}$ of the subject to be tested in a limited time. Most of the faults of the MCQs are due, not to the system itself, but to slackness of the examiners in setting the questions.

Whether we like it or not, multiple choice questions are here 3 . to stay, at least until something better comes along. It thus be- of hoves our students to become thoroughly familiar with this system and to practise the technique of this type of examination just as they have to practise answering essay questions of and viva voce examinations. Fortunately, a number of $\underset{\oplus}{\varnothing}$ excellent books are now available on MCQs for medical 음 students in varying specialities and to these can now be added Professor Rains' useful book. The questions are based on the $\overrightarrow{\vec{c}}$ text of what is undoubtedly the most popular surgical textbook in the world, Bailey and Love's "Short Practice of Surgery" which Professor Rains edits in collaboration with Professor David Ritchie. There is a useful introduction on the various types of MCQs and on how to answer them. The $\vec{\varphi}$ questions themselves are divided into 5 groups. The fire 2 parts are questions based serially on the chapter arrange ments in "Short Practice", the first group being singe response and the second providing a choice of answers (determinate type questions). Parts 3 and 4 are similar questions but now set at random with no relationship to the $\bar{\partial}$ chapter form of the textbook and thus more akin to the type of questions students will encounter in an examination.

Having got the 1001 questions off his chest, Professor Rains then provides a most useful additional section of $101 \overrightarrow{\overrightarrow{0}}$ questions in surgical history which should certainly help 3 to kindle an interest in this fascinating subject and whose $\vec{\partial}$ answers can be found from the interesting historical footnotes in the text book itself.

This is a book which will certainly appeal to clinical students and Fellowship candidates. Established surgeons might well 3 be tempted to see if they can gain $100 \%$ marks; they are likely, however, to be bowled out by some of Professor Rains' googlies.

Mycotoxic Fungi, Mycotoxins, Mycotoxicoses. An Encyclo- 음 pedic Handbook

Volume 2: Mycotoxicoses of Domestic and Laboratory Animals, Poultry, and Aquatic Invertebrates and Vertebrates. Edited by T. D. WYLIE and L. G. MOREHOUSE. $\mathcal{O}$ Pp. 570, illustrated. Marcel Dekker: New York and Basle, 1978. SFrs: 230 (set of 3 Vols. \$156.00).

This second volume of a 3-part handbook on mycotoxins and associated diseases deals with mycotoxicoses of domesticated and laboratory animals. The format chosen deals with the effects of individual mycotoxins on different species of animal, rather than on organ systems. This has led to some duplication of data, but since the handbook is expressly intended to be encyclopaedic, the approach is both logical and advantageous. 